\title{
CALDAS Y HUMBOLDT
}

\author{
ALFREDO D. BATEMAN \\ Miembro de Número y Secretario de la \\ Academia
}

Al conmemorarse por todo el mundo científico el primer centenario de la muerte del ilustre sabio alemán Federico Alejandro Enrique, Barón de Humboldt, consideramos oportuno hacer un recuento de sus relaciones con nuestra máxima figura en el campo de las ciencias, Francisco José de Caldas.

Corría el año de 1801. Caldas, retirado de sus quehaceres de mercader, pasaba sus días en Popayán dedicado al estudio de las ciencias y a sus observaciones astronómicas, meteorológicas y barométricas, cuando entabló relaciones con el Director de la Expedición Botánica, José Celestino Mutis. Por carta de éste tuvo conocimiento del arribo a las costas granadinas y del próximo viaje a Santafe y al sur de los sabios Humboldt y Bonpland. Grande fue el entusiasmo de Caldas al saber de su posibilidad de ponerse en contacto con dos hombres de ciencia del viejo mundo, de quienes esperaba aprender mucho.

Pero he aquí que un pleito que amenazaba el patrimonio de su familia y que debía ventilarse ante la Real Audiencia de Quito lo obligaron a viajar a dicha ciudad, en su carácter de hijo varón mayor y de jurisconsulto de la familia.

En carta a Mutis, fechada en Popayán el día 5 de agosto de 1801, le dice:

"Mi partida para Quito ês el 10 de agosto, y no me ha sido posible esperar en ésta al Barón de Humboldt; en Quito tendré la satisfacción de conocerlo y de aprender algo".

Entusiasmado Caldas con todá perspectiva de abrirse nuevos horizontes en el campo de la ciencia, siguió paso a paso el viaje de Humboldt, pidiéndole a todos sus amigos noticias de las actividades del Barón y encareciéndole principalmente a los de Popayán le dieran a conocer sus esfuerzos hechos en el campo científico.

En carta fechada en Quito el 28 de octubre de 1801, dirigida a su amigo Antonio Arboleda le dice:

"Acabo de recibir un resumen de las observaciones que el Barón ha hecho de Cartagena a Santafé, remitidas por mi amado Santiago... Las observaciones de Humboldt son un verdadero tesoro para mí: contienen las distancias entre los lugares que ha atravesado, la anchura del Magdalena en varios puntos; en Mompós dice tiene 554 toesas y en Angostura de Carare 72: las velocidades de la corriente, su calor en todas situaciones; las comparaciones con el Orinoco: siguen las contenidas en el Nivellement Barométrique que usted me remitió y que ya yo había recibido de mano de nuestro Santiago: las declinaciones de la aguja y sus inclinaciones, y en fin, una tabla copiosa de las latitudes y longitudes, éstas determinadas por el cronómetro de $\mathbf{M}$. Berthoud. Ya puede usted considerarme qué ocupado me tendrán estos datos y cuanto calculare: créame usted que deseo con ansia a este sabio viajero para aprender algo y aspirar a ser alguna cosa importante. Yo creo que me tratará con distinción atendiendo a lo que dice mi Santiago, cuyas palabras son éstas: "El (Humboldt) va deseosísimo de conocer a usted. Mutis le ha hablado a su favor, y puede contar con un amigo franco que no le ocultará sus conocimientos, cuanto pueda contribuir para las ideas que de usted tiene formada sobre la carta del Reino...".

En carta de diciembre 6 de 1801, fechada en Quito y dirigida también a Arboleda, luego de lamentarse no hubiera estado éste en Popayán al paso del Barón, escribe Caldas:

“...No deje usted de comunicarme la respuesta del Barón; él ha escrito una valiente carta al Presidente, cuya copia tengo y verá usted en el venidero; yo también le dirijo una a Pasto: es un poco larga y no la puedo remitir, pero un corto análisis le dará a usted idea de ella. Me introduzco pintando la grande idea que he formado de sus luces y de la bondad de su corazón por las cartas de mis amigos; que éstas me han encendido un vivísimo deseo de conocerle, de admirarle de cerca su sabiduría y sus virtudes; que no extrañe el que le hable con entusiasmo un hombre que ha nacido en el centro de la América, que recibió de la naturaleza un amor insaciable de saber, que he creído de mi obligación manifestarle mis sentimientos y el aprecio que hago de su persona. Después hablo de las ventajas que resultarán a la Nueva Granada de la visita que ha hecho al sabio autor de la Flora de Bogotá; aquí despliego mis ideas e interrumpiendo el discurso digo: "Daos priesa, yo espero con impaciencia el día de vuestra llegada a esta capital. Que no pueda suprimir las leguas que nos separan y el tiempo que necesitáis para caminarlas! Si esto no puedo, a lo menos voy a minorar nuestra distancia, voy a transportarme a Ibarra... Si acaso las grandes y poderosas recomendaciones que os han precedido por todas partes no han incluído esta villa, avisadme para prepararos una habitación no digna del mártir voluntario del galvanismo, sino proporcionada a la pobreza de los habitantes del país que recorréis. Dichoso si puedo serviros en alguna cosa mientras permanecéis entre nosotros! Mil veces más dichoso si libre de la cadena que me ata a este suelo enemigo de las ciencias, puciera seguiros a las regiones mas distantes adonde os airastra esa sed insaciable de saber.

"Ilustre viajero, sed feliz: que la prosperidad que os ha acompañado hasta aquí os siga hasta las extremidades de la tierra adonde os dirigís, que después de haber recorrido todas las partes del globo, de haber observado todas las naciones que le habitan, de haber visto a la Naturaleza en grande y en todos sus aspectos, os restituyáis a vuestra patria, que aquí lleno de reconocimientos y de gloria cojáis los frutos de vuestros largos 
trabajos, que la imprenta lleve por todas partes vuestro nombre y vuestra sabiduría, y el mármol y el bronce os pasen a la más remota posteridad. Iguales felicidades deseo a vuestro amigo y compañero de viaje $\mathrm{Mr}$. Bonpland, a quien testificaréis de mi parte el amor y el afecto que le profeso, y ambos podéis contar con todo lo que puede vuestro admirador, F.J.C."...

Al fin recibe Caldas aviso de que Humboldt salió de Popayán, y tal como lo había planeado emprendió viaje a Ibarra para encontrarle allí. El mismo Caldas, en carta dirigida a su amigo Santiago Arroyo de fecha 21 de enero de 1802 relata este momento estelar de su vida:

“...Me transporté a Ibarra, como anuncié a usted, por antelar el momento de conocerlo; salí algún trecho de aquí, y le hallé el 31 de diciembre de 1801, a las once del día. Qué momento tan feliz para un amante entusiasta de las ciencias! Yo fui el primero que me le presenté y sin detenerse un instante me preguntó: usted es el señor Caldas? A lo que contesté lo que correspondía. Desde este instante me comenzó a tratar con una franqueza y liberalidad sin igual. Qué noticias tan exactas trae de mí y de mis cosas! qué opinión tan ventajosa formada por los informes de mis amigos! Yo confieso a usted que mi amor propio nunca me habría sugerido expresiones más honrosas a mis conocimientos. Así que llegamos a Ibarra comí con él, y públicamente se volvió a mí y me dijo: He visto los preciosos trabajos de usted en astronomía y geografía. Me los han enseñado en Popayán. He visto alturas correspondientes tomadas con tal precisión, que la mayor diferencia no pasa de cuatro segundos. Después que abrió sus cofres, me mostró el manuscrito de observaciones astronómicas: me hizo notar la que había hallado de Popayán con su famoso cronómetro, y luego me dijo: el padre de usted, sin su consentimiento, me ha enseñado un libro manuscrito, en que hallé una observación de la inmersión del primer satélite de Júpiter, calculada; y da la misma longitud que mi cronómetro: lea usted. He visto un elogio en francés, que no merezco. En sustancia le diré su contenido; ya se ve lleno de rubor; pero que con un amigo como usted, depositario de todos mis pensamientos, no puedo ocultar nada, aunque se ofenda la modestia. Después de referir a su observación del cronómetro añade: el doctor Caldas ha hecho en tanto una bella observación del primer satélite de Júpiter: él ha hallado $5 \mathrm{~h} .14^{\prime} 16^{\prime \prime}$ : y yo $5 \mathrm{~h} .14^{\prime} 13^{\prime \prime}$. Il est ettonant que ce jeune americain, se haya elevado hasta las más delicadas observaciones de la astronomía por sí mismo, y con unos instrumentos hechos de sus manos; con otro montón de cosas que no quiero referir. Así escribió en Popayán por una simple observación aislada, que dejé por casualidad en esa ciudad. Es preciso que le haya tocado más una serie de ellas que le he presentado, en que las diferencias de altura correspondientes no pasan de un segundo, con mi cuarto de círculo de madera dividivi...".

Habiéndose reunido en Ibarra, en la forma descrita, Caldas con los dos sabios extranjeros retornó a Quito, habiendo estado con ellos todo el tiempo de su permanencia en esa ciudad, acompañándolos en muchas de sus excursiones por los cerros andinos, y asociado a sus trabajos y estudios. Caldas recibió a Humboldt con una notable memoria en que proponía iniciar la reconstrucción de los monumentos erigidos medio siglo antes, re- lativos a la expedición de La Condamine, y que el mal fundado orgullo español había ordenado destruir.

Caldas entregó a Humboldt una copia de su mapa del Alto Magdalena, con las respectivas observaciones astronómicas y cálculos sobre la posición de Popayán, y otros puntos intermedios hasta Ibarra. Este mapa fue publicado por Humboldt en su atlas geográfico de 1814, anotando allí el nombre de Caldas y haciendo referencia a todas las posiciones fijadas por él. Todos los trabajos ajenos que recibió Humboldt quedaron consignados escrupulosamente, comparados los resultados con los suyos propios, examinando sobre su exactitud absoluta o relativa. Caldas fue asociado con Humboldt en muchos de estos trabajos que para él eran nuevos, comparando sus instrumentos con los del viajero teutón.

En más de una ocasión Caldas trató con Humboldt acerca de su método para medir la altura de las montañas. Caldas había escrito con anterioridad a su amigo Arroyo sobre sus teorías al respecto y como éste le diera algunas informaciones, en carta fechada en Quito el 6 de octubre de 1801 le dice:

"La noticia que usted me comunica de que el Barón de Humboldt sumerge en el agua hirviendo el termómetro, y rectifica con él la altura del barómetro, me hace pensar con fundamento que le es conocida la ley de las elevaciones del licor del termómetro en el agua, y que sabe aplicarla al cálculo de las elevaciones en los lugares. Qué cierto es que nosotros vivimos dos siglos atrás de la Europa!...".

En una ocasión trató con Humboldt acerca de su método o invento para medir alturas con el uso del termómetro, observando el punto de ebullición del agua. Para Humboldt la cosa no era del todo nueva, habiendo él usado, desde el principio, un procedimiento parecido. Según su diario, el 22 de junio de 1799, sobre el pico de Tenerife, después en la cima de Guadalupe y últimamente en su ascensión al Puracé, había hecho observaciones usando un aparato que había mandado construir por el hábil mecánico Paúl, de Ginebra, y utilizaba la fórmula de Déluc, aunque miraba con cierta desconfianza ese Boulloire thermoscopique que le había sido recomendado por Saussure en París. Lo usaba mas bien para comparar los resultados con los obtenidos con el barómetro y tenía, dice en sus notas, poca confianza en la exactitud de esas observaciones termométricas por el riesgo de errores notables, mientras una mayor perfección de tales instrumentos no permitiera leer en la escala pequeñas fracciones de grados.

Humboldt le dijo a Caldas:

"Succio (Saussure) no ha pensado como usted en agua hirviendo, sus trabajos se han limitado al temple de la atmósfera; asigna 640 pies de altura por un grado en el termómetro, y yo he observado en el Pico de Teida que da muy bien este coeficiente cuando el día es sereno y no se obra en lugares elevados."

Oído este concepto de Humboldt Caldas se confirmó en la idea de la originalidad de su método.

Al explicar Caldas a Humboldt cual era su método, y luego de convenir el Barón de que el coeficiente de 
Caldas era más exacto que el de Saussure, le objetó diciéndole que el calor del agua variaba a la misma presión hasta un grado. Caldas refutó esta aseveración diciendo:

"Una larga práctica me ha enseñado que el calor del agua a igual presión es invariable, observando con las precauciones convenientes. $\mathrm{La}$ autoridad de todos los físicos apoya mi modo de pensar. De otro modo, podía haber termómetros comparables? No es esta invariabilidad del calor del agua hirviendo a la presión de $28^{\circ}$ el fundamento del término superior de la escala de todos los termómetros? Es verdad que a los primeros hervores no ha adquirido el agua todo el calor de que es capaz; pero avivando el fuego, aumentando el hervor hasta su máximum, adquiere siempre el mismo calor."

Caldas concluye su memoria sobre este método con el siguiente Apéndice. - "No quise perder la brillante ocasión de comparar mis miserables instrumentos con los del señor Barón de Humboldt, y hacer lo mismo con las observaciones verificadas en los lugares que nos eran comunes. Sólo en Popayán habíamos observado ambos el calor del agua. Este ilustre viajero había hallado que el agua llovediza había hecho subir el licor del termómetro en esta ciudad a $203^{\circ} .3$ de Farenheit, cuando el agua destilada me daba $202^{\circ} .21$, es decir, casi un grado menos. Me sorprendí al ver tan enorme diferencia, pues el agua de lluvia no puede producir un grado de más en el termómetro. Estará el error -me decía-en nuestros instrumentos? Si lo hay, seguramente recae sobre mi termómetro. Deseando salir de la duda, suplico al señor Barón me confíe el mismo termómetro que le había servido en Popayán para su observación; me concede traerlo a mi casa; lo pongo al lado del mío, dejo que adquieran la temperatura de mi aposento, y hallo que el del señor Barón está justamente un grado más alto que el mío. Pero cuál de los dos está fuera de la temperatura verdadera? El hielo es el mejor camino que se me presenta para salir de mi incertidumbre. Sumerjo ambos termómetros en él, y veo con admiración que el bello termómetro de Nairne se detiene en un grado sobre la congelación o a $33^{\circ}$ de Farenheit, cuando el mío bajaba con mayor exactitud a $0^{\circ}$ de Reaumur y $32^{\circ}$ de Farenheit. Por consiguiente es necesario quitar $1^{\circ}$ a los resultados de las observaciones hechas con este instrumento. Así $203^{\circ} .3-1^{\circ} .0=$ $202^{\circ} .3$, y quitando $0^{\circ} .1$ por haber sido con agua de lluvia, quedan nuestras observaciones perfectamente acordes; la del señor Barón será $202^{\circ} .20$ y la mía $202^{\circ} .21$. He ahí dos termómetros de autores de escala de tiempos diferentes dar el mismo calor al mismo nivel, cuando nuestros barómetros se sostienen bien diferentes. El señor Barón halla que su barómetro en Popayán se mantiene en 23 p. 3 1. 4; el mío a 22 p. 111.7 y el de Bourger a 22 p. 101.7 ; casi 5 líneas más bajo que el primero. Cuál es el termómetro que graduado con inteligencia dé tan grande diferencia? Ah! parece que la experiencia comienza a confirmar que el calor del agua en diferentes termómetros es más constante, menos variable, que la columna de mercurio en barómetros distintos..."

En las relaciones del viaje de Humboldt se halla consignada, en varias ocasiones, la observación de ser mucho menos perceptibles las variaciones barométricas en la zona tropical que en las latitudes mayores. El trataba de darse cuenta de esa particularidad sin llegar a solución alguna que le fuera satisfactoria. Siendo su paso tan rápido por las regiones ecuatoriales, no alcanzó a ver las conclusiones a las cuales Caldas SI penetró más tarde, y que fueron recogidas como fruto precioso de observaciones pacientes, menudas y perseverantes, durante dos años de recorrer una zona bastante reducida y precisamente en las cercanías de la línea ecuatorial. Las dudas anteriores de Humboldt acerca de la menor movilidad barométrica en la zona tropical, quedaron aclaradas y resueltas pocos años después con la definición formulada por Caldas: "las variaciones barométricas aumentan en razón directa de la latitud".

No menores que sobre el punto anterior eran las dudas de los dos naturalistas, Humboldt y Caldas, sobre las imperfecciones de medición en grandes alturas. Estaban de acuerdo en cuanto que hubiese diferencias no explicables para ellos, no ENTRE sino EN ambos métodos. Humboldt siguió su viaje sin haber hallado la solución, pero Caldas quedó persiguiendo la idea. Con el tiempo su perseverancia le concedió la victoria, y pudo él, confirmando lo que Bouguer apenas había presumido, dar expresión clara a esta segunda fórmula "las variaciones barométricas disminuyen en razón directa de su altura".

Para Humboldt la medición de las alturas no era asunto de capital importancia, como muy bien podía serlo para Caldas, en esta primera época de sus estudios como naturalista. El viajero alemán conocía y usaba, cuando llegó a la Nueva Granada, dos métodos practicables: el barométrico y el termométrico, ambos con las imperfecciones de su tipo. No sería este un punto que mereciera ser tratado a espacio, si no fuera por una leyenda formada en otro tiempo en Colombia, tomada por verdad y repetida por muchos, con grave perjuicio para la buena reputación de Humboldt.

Pombo, el primer biógrafo de Caldas, afirma que el naturalista alemán no solamente no apreció el invento de Caldas para medir las montañas, sino que abusó de la confianza de éste para usarlo él mismo; probablemente Pombo no tuvo conocimiento exacto de como sucedieron las cosas en realidad. En verdad, Caldas demostró que la altura se puede medir por medio de la temperatura del agua en ebullición y hasta planteó una fórmula, naturalmente imperfecta por lo reducido del espacio que recorrió, el número de observaciones y la incorrección de sus aparatos. Caldas sí tuvo esta idea original, pudiéndose decir fue el inventor o precursor del hipsómetro, aunque la Física Universal atribuye este invento a Regnault, no por traición de Humboldt a la confianza que le otorgó Caldas, sino a circunstancias diferentes, especialmente a la intervención de científicos franceses que visitaron nuestra patria años después de muerto Caldas, y antes de que se apreciara el valor científico de éste.

Con Bonpland Caldas aprendió a conocer muchos pormenores de botánica, para cuyo estudio sistemático y manejo técnico le habían faltado al segundo, hasta entonces, la mayor parte de elementos indispensables. A Humboldt no le gustaba mucho ocuparse en los pequeños detalles de esta ciencia, los cuales sabía bien tratados por su compañero, especialista en el ramo. Hum- 
boldt miraba la vegetación a grandes rasgos, desde un punto de vista más elevado, como otra rama, entre tantas, para sus cuadros generales de la naturaleza. En sus conversaciones con el amigo neogranadino tocaba también la idea que traía en la mente, desde Santafé, sobre una Geografía General de las Plantas, cuyo primer prospecto elaboró en el curso siguiente del viaje, para enviarlo a Mutis desde Guayaquil.

Por ese entonces, con fecha 21 de enero de 1802, escribe Caldas a su amigo Arboleda diciéndole:

“...Si yo diera curso a mi imaginación, si dejara desahogar a mi corazón conforme al temple en que se halla, llenaría volúmenes, y esto sería en perjuicio de lo mucho, de lo inmenso que tengo que decir a usted del Barón de Humboldt, de este genio original y raro que ha venido a ilustrar nuestros hogares. Confieso a usted que cuanto se ha dicho de este hombre grande es muy inferior a lo que es en realidad. Yo ensancho los límites de mi pobre imaginación, y a pesar de mis últimos esfuerzos no cabe en mi cabeza el mártir voluntario del galvanismo. Qué astrónomo tan delicado y tan sagaz! He visto gran parte de sus bellos instrumentos, se ha dignado enseñarme su uso y he tenido el honor de ser su coobservador. Cuánto he crecido en esta ciencia predilecta en los pocos días que ha trato a este Newton, a este Casini de nuestra edad! Apenas me conozco. En lugar de 120 estrellas que tenía en mi catálogo, soy dueño de 560, todas fijadas por el ciudadano Michel François Lalande; este precioso tesoro me lo ha franqueado el Barón; todos sus libros están a mi disposición, la Guía de Navegantes, el Atlas Celeste de Flamsted, y el famoso cronómetro de 1.000 duros en Londres, me lo ha franqueado con una generosidad que no tiene igual. He visto el cúmulo inmenso de observaciones astronómicas hechas en toda la extensión de su viaje, y espero quedar formado en este precioso ramo, para el cual he tenido una ardiente aplicación. Mis trabajos astronómicos han sido coronados de gloria con el aprecio y aprobación de Humboldt. Nunca había imaginado que en Popayán, en medio de la miseria de mis instrumentos, pudiera haber llegado a merecer no sólo la aprobación, sino el elogio de este viajero ilustre. He visto en sus diarios mi elogio, y me hace representar un papel que yo mismo no me había imaginado, y que mi amor propio no se había atrevido a sugerir. Al Padre le dije de Ibarra lo que contenía en sustancia.

"Así pensaba antes de conocerme, y con sólo una observación del primer satélite de Júpiter que vio en un libro que dejé en poder de mi padre. Juzgue usted ahora de lo que pensará después que le he presentado una serie de mis más preciosas observaciones, que tienen un grado infinitamente mayor de precisión. Me ha dicho que en todas las Secretarías de América le han mostrado cartas geográficas que tenían guardadas como tesoros; pero que sólo la carta de Timaná le merece este nombre, que es la única astronómicamente construída, y le ha dado un lugar distinguido en su gran carta. Me ha dicho que quiere que me conozca el mundo entero. Qué honor, qué gloria para mí, Antonio querido, ver mis trabajos parecer a la faz del universo acompañados de los del Barón! Tanto más me ha conmovido esto cuando jamás creí que viesen la luz pública nuestras trasnochadas, ni que se gravase a Timaná. Qué trabajos tan bien empleados, mi Antonio; felicitémonos, sí, feli- citémonos. He comparado mis alturas del barómetro con las del Barón hechas en Guadalupe, Santafe, Popayán, Pasto, Pastos, Chota, Ibarra y Quito y hemos hallado una conformidad prodigiosa. He merecido el honor de que en Santafe preguntase por la casa en que hice mis observaciones en 1796; y se transportase a ella con su barómetro para compararlas con las mías. Tanto es la confianza que le han merecido mis trabajos. Otra cosa bien singular, y que ha de agradar a usted, es que el Barón conoce al Magdalena desde su embocadura hasta Tocaima, y yo le he presentado la carta de este río desde este punto hasta su origen, y en suma, toda la parte alta va conforme a mis determinaciones. Qué impresión le ha hecho a este sabio que pudiese llegar al grado de perfección que ha visto con un cuarto de círculo de madera hecho en Popayán! Ha dicho en una tertulia aquí que mis observaciones están mejor ejecutadas que las de Jorge Juan, y que nunca habría creído que en América hubiera ido la astronomía tan adelante. Estos son los honores que hasta aquí he merecido a este viajero, y ellos hacen mi panegírico; pero yo los sepultaría eternamente en el fondo de mi corazón si no hablase con un amigo que tiene tánta parte en mis observaciones y que el fondo de confianza que nos profesamos me quita la nota de vano; cuánto calle usted sobre este punto, y sólo a mi Páter, a mi don Francisco comunique estos primeros frutos, y estos triunfos; con los demás guarde un eterno silencio. Cuente usted en el número de los primeros al Abate y Buchon. Cómo pudiera volar y transportarme a su casa para contar un pormenor de que tanto me ha enseñado este sabio prusiano! No es posible mi Antonio decir a usted cuánto me ha dicho: esto hará el objeto de nuestras cartas en lo sucesivo. Pero no es posible resistirme a decir algo de botánica. Profesa esta ciencia como lo habría hecho Jusieu o de Lamark. No hay planta que le pregunte que no le señale su género y muchas veces hasta la especie. Sabe de nuestros trabajos botánicos, y en especial de usted. Le he hablado del Miroxylon, le he dicho mi juicio sobre su especie, y se ha admirado del impar de las hojas. Qué dolor el haber usted malogrado el lance de mostrárselo vivo y personalmente! Yo le he dicho tenemos esqueletos, y desea verlos, y he aquí usted en la obligación de remitirme dos de ellos por lo menos. Ah! Ojalá este sabio quiera publicarlo con el nombre de usted y llamarlo Miroxylon Arboledeum! A usted toca el examen y conocimiento de este precioso vegetal, y yo haré todo mi posible para hacérselo entender así al Barón. Mucho ha sentido no haber conocido a usted y a Julián y toda la amable familia de Arboledas, estas fueron sus expresiones...".

En carta fechada en Quito, el 6 de febrero de 1802 y dirigida igualmente a Arboleda, continúa relatándole sus relaciones con el Barón:

"He observado con este astrónomo profundo, he visto a Júpiter, a sus satélites, a Saturno, y puede usted persuadirse que nuestros telescopios compuestos con nuestras lentes microscópicos son mejores? No hay que dudarlo; yo ví con los míos duplicado el diámetro de Júpiter y el anillo de Saturno. Ah, que no me hubiera yo traído a pesar del cielo, de la tierra y de Cali entero esa pieza digna de mejor dueño! Qué genio enemigo de las ciencias presidirá en la venta de estos instrumentos!... 
"El Barón me ha ofrecido una completa lista de los libros más bellos que se han escrito sobre todos los ramos de las ciencias; pero es imposible hacerlo en este correo; suspenda usted el remitir listas precipitadas, de los que en su particular haya formado; es preciso me consulte sobre todo...

"El 9 de ésta salgo con el Barón a nuestra primera expedición alrededor de Quito; ya puede usted considerar cómo estaré preparándome para esta correría. La botánica sacará mucho. Se preparan el Barón y Bonpland a hacer la disección de la llama, y yo de testigo de esta operación...

"Ayer he visto el M.S. del Barón sobre las alturas del barómetro hechas en Santafe; tiene agregado mi papel sobre Guadalupe, y una noticia circunstanciada de mi cálculo. Ah! mi Antonio! que reconocimiento no debo yo tener con este hombre que tanto aprecio ha hecho de mis observaciones! El ha recogido cuanto ha podido de mis cosas, y yo no le he observado nada...".

Durante este tiempo en que Caldas estuvo con Humboldt en Quito, mostrándole sus trabajos, recibió continuos elogios de él, ya que el sabio alemán dijo las siguientes frases que Caldas transcribió a su amigo Arboleda en carta fechada en Chillo a 6 de marzo de 1802:

"Este Mr. Caldas es un prodigio en la astronomía. Nacido en las tinieblas de Popayán, ha sabido elevarse, formarse barómetros, octantes, sectores, cuartos de círculo de madera; mide latitudes con gnomones de 15 o 20 pies. Qué habría hecho este genio en medio de un pueblo culto y qué no debíamos esperar de él en un país en que no se necesita hacerlo todo por sí mismo! El genio no puede extinguirse y se abre las puertas para seguir la gloriosa carrera que los Bouguers y de La Condamine han abierto. La Audiencia de Quito ha podico destruir las pirámides, pero no sofocar el genio, que parece propio de este suelo".

\section{$\mathrm{Y}$ añade Caldas:}

"Puedo desear corona más gloriosa ni premio más grande de mis pequeños trabajos? Qué dirá este viajero cuando complete su carta del Magdalena con mis observaciones? Estas le arrancaron la expresión de hacerme en esta parte superior a Jorge Juan. Qué honor!"

Lo mucho que Caldas aprendió de Humboldt, la amistad que nació entre estos dos personajes, llevaron al primero a acariciar una ilusión; acompañar al Barón en sus futuras excursiones. En carta fechada en Quito el 21 de marzo de 1802, dirigida a Arboleda, le dice:

"Esta sed, este furor de saber y de ser útil me devora; usted conoce bastante a Caldas para convencerse de ello sin prueba: las cadenas, la más fuerte de todas, la pobreza, me ata a este suelo desgraciado para las ciencias; yo, semejante a un león de Numidia en el parque del gran señor que prueba todos los modos de libertarse, dejar la prisión y restituirse a sus bosques nativos, que cansado de esfuerzos inútiles queda debilitado y tendido sobre la arena por largo tiempo; que de repente se avive de nuevo en su corazón el amor de la libertad; que lleno de furor e indignado contra su debilidad reúne sus fuerzas y hace espantosos movimientos, estremece el vivar y parece que va a dar fin a cuanto le rodea. Esta es la fiel pintura de mi alma. En un momento de furor y de desesperación tomo la pluma y emprendo cosas que a los ocho días miro como quimera. Un día, el 28 de enero de 1802, agitado mi pobre corazón, revolvía en él los modos de ilustrarme y de seguir a Humboldt; por todas partes no veía sino muros de bronce y obstáculos insuperables. De repente imagino que Mutis podía apoyar mis ideas, que quizás sería útil para la misma expedición de que se halla encargado, y puse a mi amadísimo Arroyo la que usted ha visto. Yo no imaginé jamás suscripción alguna, y sólo pensé en que Mutis y el Consulado me apoyasen, por interposición de los amigos. Jamás pensé que se realizase ni que tomase el cuerpo que ha tomado; sólo se trataba de tocar con el Virrey y el Consulado, e ignorando todavía el suceso, para qué había de ocupar mis cartas con asuntos que miraba en perspectiva, y con perjpuicio de las noticias de Humboldt?...".

Entre tanto continúa trabajando con Humboldt. En la misma carta cuenta a Arboleda sobre nuevas descripciones de plantas, especialmente de la Asnayuyu, que es un Tagetes, así como le informa que ha subido a Antisana a una prodigiosa elevación. Dice así:

"Condamine se gloriaba de haber estado en una altura a que ningún mortal había llegado; su barómetro en ella se sostuvo en quince pulgadas diez líneas, y el de Humboldt en catorce pulgadas once líneas, más bajo que el de aquel; por consiguiente, este sabio y valeroso viajero excedió al astrónomo de París en cerca de doscientas toesas, o cuatrocientas setenta vueltas; hoy es el mortal que se ha elevado más sobre el nivel del mar; será acaso el que se haya también elevado más en las especulaciones científicas? Será el genio primero de nuestro siglo? Yo le acompañé en la medida de una base para la determinación de la altura de Pichincha, y a otras observaciones diversas. Tomó aire en aquella enorme elevación, su análisis se hará en Quito, y el siguiente nos dará materia para una larga carta...".

Sus gestiones con Mutis para que apoye su viaje acompañando a Humboldt tiene éxito favorable, ya que éste le ofrece sufragar sus gastos al mismo tiempo que le escribe al Barón recomendándole la compañía de Caldas. Viene entonces para éste la gran desilusión de su vida, que él mismo relata en su carta a Mutis fechada en Quito el 6 de abril de 1802:

“...Ah! día 3 de abril de 802 ! te borrarás alguna vez de mi memoria? Este día, día glorioso y terrible, hará época en mi vida. A las dos de la tarde se aparece en mi casa un criado del Barón de Humboldt, me entrega un pliego, conozco la letra del ilustre Mutis, mi corazón se conmueve, abro, veo este nombre: J. C. Mutis, mis lágrimas asoman, no puedo contenerme, beso esta firma respetable, leo, cielo santo! sólo tú eres testigo de lo que pasó en mi alma; mis ojos se aniegan; mi garganta se anuda; corro como loco; no hallo a un amigo a quien dar parte de mi felicidad y con quien disipar una parte del fuego que me abrasa; voy a casa de Humboldt, no le hallo; vuelvo a la mía; no atino, no puedo fijarme en nada; todo es amar a Mutis, todo es admirar su generosidad. Qué cúmulo de ideas se me presentan! Qué gloriosos trabajos los que voy a emprender! He aquí al mortal más feliz. Vuelvo a la casa del Barón; le hallo; pregunto por el sabio Mutis, por 
sus cartas. Me contesta este viajero con frialdad; me suprime el asunto principal; me lo niega directamente. En los primeros momentos de mi sorpresa creo al prusiano. Qué asombro el mío! Veo de letra del ilustre Mutis estas cláusulas, que quedarán eternamente grabadas en mi corazón. Se cumplirán los ardientísimos deseos de usted si mi amadísimo el señor Barón de Humboldt nos franquea su consentimiento; tengo en mis manos un cuantioso libramiento. Oigo de boca de este sabio joven: no me dice nada el señor Mutis, no me ha escrito sobre el viaje de usted. Qué distracción tan espantosa la de mi ilustre protector, decía dentro de mí! No puede ser; vuelvo a reconvenir y a preguntar, reconvengo con mi carta, con el libramiento. La fuerza de la verdad le oprime, y me dice: $M i$ amigo, yo he mentido a usted; el señor Mutis me habla a la larga del asunto, pero yo, que he resuelto viajar solo, no quería dar a usted esta pesadumbre. Qué rayo, qué golpe tan terrible sufre mi corazón! Del colmo de mi gloria en un momento paso a la melancolía más profunda y a la desesperación. Qué reflexiones tan espantosas me oprimen! Todo el vasto edificio de mis proyectos se desploma, todo desaparece como el humo. Qué contraste el que se presenta a mi imaginación! Mutis, celoso, amante de las ciencias, abre sus tesoros. Humboldt, amante de un desembarazo pueril, le oprime el modesto equipaje de Caldas, le parece complicado el aparato de una persona más. Mutis se pone en movimiento, escribe, empeña su respeto por ilustrarme. Humboldt sacrifica mi fortuna, mi gloria a una comodidad imaginaria. Mutis, amante de su especie, quiere prolongar sus beneficios más allá de su muerte, reproduciendo sus conocimientos en jóvenes aplicados. Humboldt me deja con tranquilidad en medio de mis cadenas. Sí, ilustre protector mío, estas son las ideas bajo de las cuales me representaré toda mi vida al ilustre Mutis y a Humboldt. Jamás pensé que un hombre que me había apreciado tanto; que recogía mis pequeños trabajos con ardor; que los ponía al lado de los suyos; que me había hecho un elogio en sus diarios superior a mis méritos; que más de una vez había dicho que era lástima no se me protegiera y que se me armase de instrumentos; que había escrito a Popayán para que se me costease a Europa, sin saberlo yo mismo; que me inspiraba ideas gigantescas y gloriosas de trabajos futuros, jamás, digo, creí que me negase su lado y que no me permitiese acompañarlo al Perú y a Méjico, acabando por franquear oficiosamente este favor a un joven ignorante, sin principios y disipado. Corramos de una vez el velo a este misterio. Yo hablo con el hombre prudente y reservado que ocultará eternamente lo que voy a escribir. El carácter de Humboldt y el de Caldas son muy diferentes. El primero tiene una viveza que ya toca en inquietud, locuaz, amante de la diversión y de la sociedad; el segundo, con un fondo de actividad, conserva un cierto grado de lentitud en sus operaciones, taciturno, de una vida un poco austera, y amante del retiro; su semblante frecuentemente tranquilo; rara vez risueño, no salta, no canta, no corre, no lucha. Este es el origen, diga lo que quiera el Barón de Humboldt de su negativa; así lo dijo a un amigo. Si no es así, de dónde la estrechez, las satisfacciones con unos jóvenes que no saben sumar, que no conocen un ángulo? La amistad más viva, el amor más verdadero no puede igualar al que el Barón ha manifestado en Quito con esta especie de gentes. Este es un hecho público y de que darán testimonio todos estos habitantes. Es joven, es extranjero; no es inglés. Una conducta severa y tranquila no es del gusto del Barón. Bien presto conocí que el modo de agradarle era hablar, reír, correr. Pero yo no puedo contrahacer mi carácter; paso antes por disgustar al Barón. Yo he entrado dentro de mí, he examinado mi conciencia, y me he preguntado, qué has hecho al Barón para que no quiera llevarte a su lado? No he hallado, ilustre protector mío, no he hallado sino elcgios, admiración, pequeños servicios, porque no soy capaz de grandes obsequios. Todo lo que alega para eximirse me ha parecido más excusas que razones, me ha avergonzado y he resuelto no volver a hablar sobre el particular con este viajero.

"La conducta que he guardado con él ha sido esta. Yo le he mirado como joven, no he querido abrirle mi corazón, ni mi genio; le he manifestado aquellas cosas que me parecían análogas a sus trabajos sin otro fin que el que me advirtiese mis errores y me pusiese en el camino; he hablado cuanto menos ha sido posible, porque no quería pasar la plaza de charlatán; le he hecho muchas preguntas, y me he retirado. Yo conocí desde el primer día que nos conocimos que nuestros genios no eran análogos, y he procurado no serle molesto, estoy bien seguro que no me conoce, y si aventurara sus juicios son por algunas observaciones que le he dado, y nada más. Un día, recién llegado, me leyó un elogio que había hecho de mí en sus diarios, me franqueó su libro, le copié. Quiero insertarlo a usted, no para que lo crea verdadero, sino para que vea cómo pensaba de mí este viajero. Después de referir una observación de longitud hecha en Popayán con el primer satélite de Júpiter, perfectamente acordado con la de su cronómetro, dice: "Ce Mr. Caldas est un prodige dans l'astronomie. Né dans les tenebres de Popayán n'ayant jamais voyagé plus loin que jusq'a S.Fe il se est construir lui meme des barometres, un secteur, un quart de cercle du bois. Il tire des meridiennes, mensure la lat. par des gnomones de $12-15$ pies. Que ne ferait pas se jeune homme dans un pais ou il y a des moyens, ou il ne faut pas tout apprendre par soi meme! Les ouvrages de Bouguer et de $\mathrm{La}$ Condamine ont eu une influence singulier sur les americains depuis Quito a Popayán. Le sol de ce pais est devenu clasique et on est tenté de dire qui se raporte au sol natal. L'audience de Quito a pu detruire les pyramides; mais elle n'a pas realisé d'etouffer cet etincelle de genie qui renait de temps en temps dans ce pais et qui etraine dans le carriere que les Bouguer et La Condamine ont ouvert." Esto escribía en Popayán por un simple M.S. antes de conocerme. Pienso que mi moderación lo ha hecho mudar de concepto; no estoy plenamente seguro de este punto. Pero hoy mismo entró un amigo en mi casa, y me dice: "No se confíe usted del Barón: yo he oído que decía a N. a N. (jóvenes ignorantes y los mismos de que he hablado) Caldas es un tonto y otras cosas de esta espepecie." No quiero creerlo por ahora, porque apenas conoce mi interior, y este pueblo es abundante de chismes. No será así mi conducta con mi amado protector; a él abriré plenamente mi corazón, yo le diré cuanto pienso y le remitiré mis trabajos. Por ellos y no por juicios siempre osados debe usted conocerme. Yo seré tonto, no lo negaré al Barón, pero no tiene en sus manos tontera dada por mí. Jamás le he manifestado mis modos de pensar, y siempre he oído con respeto los suyos, y he corregido los míos. Ojalá me hubiera ocultado de él para siempre! Pero ya no hay remedio. 
"Confieso que la noche del 3 fue noche tan espantosa para mí como gloriosa la tarde que le precedió; la pasé en medio de las más tristes reflexiones, me abatí. Pero estoy repuesto, he vuelto sobre mí, y en el seno de mi desgracia me he consolado, he enjugado mis lágrimas con mi generoso, mi sabio Mutis. Nuestros caracteres parecen análogos, y creo que una paz eterna reinará entre nosotros. Todo lo que sé de la vida pública y privada del virtuoso Mutis, me encanta, me arrebata. Tan agradecido de usted como resentido del desaire de este viajero, me vuelvo a mi padre, a mi protector, le muestro mis cadenas y quiero que añada a estos títulos gloriosos el de mi libertador. Sí, sabio, generoso Mutis, sacadme del abatimiento, de la ignorancia y de la oscuridad en que vivo...".

La negativa de Humboldt de aceptar a Caldas como compañero de viaje, hirió profundamente los sentimientos de éste. En carta de abril 21 de 1802 dirigida a Mutis comenta lo siguiente:

“...Qué diferente es la conducta que el señor Barón há llevado en Santafe y en Popayán de la que lleva en Quito! En las dos primeras ciudades fue digna de un sabio; en la última es indigna de un hombre ordinario. El aire de Quito está envenenado; no se respiran sino placeres; los precipicios, los escollos de la virtud se multiplican, y se puede creer que el templo de Venus se ha trasladado de Chipre a esta ciudad. Entra el señor Barón en esta Babilonia, contrae por su desgracia amistad con unos jóvenes obscenos, disolutos; le arrastran a las casas en que reina el amor impuro; se apodera esta pasión vergonzosa de su corazón, y ciega a este sabio joven hasta un punto que no se puede creer. Este es Telémaco en la isla de Calipso. Los trabajos matemáticos se entibian, no se visitan las pirámides, y cuando el amor a la gloria reanime a este viajero, quiere mezclar sus debilidades con las sublimes funciones de las ciencias. Mide una base en las llanuras de Quito, aquí viene el objeto de sus amores, o el de los cómplices de sus fragilidades. A veces compadezco a este joven, a veces me irrito. Cuando me anima esta última pasión, me parece que veo reanimarse las cenizas de Newton, de Newton que no llegó a mujer, y con un semblante airado y terrible decir al joven prusiano: Así imitas el ejemplo de pureza que dejé a mis sucesores? Quieres que vuestro nombre se fije en el templo de la gloria y en el de la diosa de Atharea? Nó, la gloria no es debida a un corazón que no sabe vencer a esa pasión que os domina. Deponed esos instrumentos, ved a pasar una vida oscura y afeminada en medio de los placeres. El sentimiento de esta desgracia me arrastra a estas imaginaciones. Vamos al asunto. Como yo he frecuentado la casa de este sabio, como hemos vivido un mes juntos en una bella hacienda, hemos tenido ocasiones repetidas de que él conozca mi diverso modo de pensar en materia de placeres. Cuando se hablaba de ellos yo no podía sino mostrar en mi semblante mi disgusto y en cierto modo mi indignación. La Providencia me dio unos padres celosos de la pureza de sus hijos, éstos a fuerza de desvelos enfocaron mis pasiones, y puedo decir que me oprimieron. A los diez y nueve años me mandaron a esa capital a continuar mis estudios; cuidaron de darme unos que hicieran sus veces en Santafe que no le cedían en celo; entré en otra feliz opresión. Mis años se aumentaban, y yo contraía un hábito dichoso de retiro y cierto gusto a la pureza; la religión completó esta obra. Violento hago a usted esta relación de conducta, pero hablo a mi padre, a quien debo hablar con sencillez y con franqueza.

"A usted debo la comparación de nuestros caracteres y las más ocasiones de diferencias. El señor Barón me juzga severo, inflexible, triste. Cómo puedo aprobar sin hacerme cómplice? Cómo puedo reprobar mostrando un semblante risueño? Este es el origen de la aversión, si así se puede llamar el disgusto que tiene el señor Barón de mi compañía; este es el origen de su negativa, diga lo que quiera, este es el origen de la idea que se ha formado sin motivo de mi debilidad y de mis aprensiones. Usted tiene en Santafe a Torres, a Pombo y a Arroyo; estos me conocen, son hombres de bien, ellos dirán a usted si mi constitución es débil. El señor Barón se desmayó en Pichincha, esta es prueba de fortaleza? Desengañémonos: un viaje que lo han hecho muchas damas delicadas, no lo podrá hacer Caldas? Yo no he probado mis fuerzas con este viajero, cómo sabe si soy débil? No quiere a un compañero silencioso que le reprenda sin hablar. Si yo viviera en el paganismo, habría creído que Venus, irritada porque no había querido sacrificar en tantos templos como tiene en Quito, había excitado esta borrasca contra mí; pero vivo en el seno de la verdad, reconozco una providencia paternal en esta negativa. Quién sabe si mi ilustración sería a expensas de mis costumbres? Este es el momento en que comienzo a amar mis tinieblas. Pero mi instrucción está vinculada a la compañía del Barón de Humboldt? Qué triste suerte si fuese esto verdad! Nó, no está vinculada a su sociedad. Qué verdad tan consoladora!...".

En carta de Caldas, dirigida a Arboleda, fechada el 6 de mayo, le anuncia que "el Barón se prepara para su marcha" y en carta al mismo, de junio 3, le dice, refiriéndose a Humboldt:

“...Este ingrato pueril parte el 8 de éste para Lima. Yo me alegro de perder de vista a este despreciable de su amigo. Algún día sabrán ustedes las causas y se asombrarán al ver que los hombres más grandes tienen debilidades. Por ahora no es posible decir nada; dos días me restan, y en ellos he de copiar ciento cincuenta géneros nuevos de gmelim que me faltan. Cuánto he trabajado, mis amigos! Qué riquezas las que he adquirido en los cinco meses pasados!...".

En relación con los últimos días que estuvo con Humboldt, dice Caldas, en carta dirigida a Mutis el 21 de junio de 1802 lo siguiente:

"El señor Barón de Humboldt partió de aquí el 8 del corriente con Mr. Bonpland y su Adonis, que no le estorba para viajar como Caldas. Yo he mantenido hasta el momento de nuestra despedida una buena armonía con este viajero. Creo no tendrá de qué quejarse, si no me hace injusticia. Yo he observado con el mayor cuidado sus pasos, y he visto gran parte de sus M.SS. En las vísperas de salir de aquí visitó una pirámide (la de Caraburú), con una velocidad increible. En veintiseis horas se hizo toda la expedición, y sólo se trajo por fruto que existía el cuadro de los cimientos, ignorando si en su centro se halla la muela de molino, que es el asunto principal. El señor Barón ha escrito mucho sobre este punto, y creo que el exacto y verdadero de La Condamine no sale muy bien. Yo deseo leer 
la causa que existe en el archivo secreto de esta Audiencia y que no se franqueó al Barón para rectificar mis ideas falsas de que está imbuido este prusiano.

"Como la causal que ha dado para no franquearme su lado ha sido que mi semblante es severo, y mi trato poco afectuoso y seco, no quiere molestar su delicadeza con mi presencia, y me excusé acompañarlo en su primera subida a Pichincha y Cotopaxi. Creyó el señor Barón que eran efectos de mi sentimiento por su negativa, y procuró de todos modos contentarme, de modo que al fin de su mansión en Quito me ha hecho mil expresiones, visitas, elogios, y procurado dejarme satisfecho. Yo le amo, pero he sentido este desaire, que no curará con nada este sabio.

"Pasó un día personalmente a mi casa a convidarme para una segunda subida a Pichincha, ponderándome la importancia de ver de cerca a este volcán. Esta habría sido la ocasión de explicarme con él; pero no quise, acepté el convite y lo seguí. Jamás me pesará haber hecho esta pequeña expedición. Qué espectáculo! Figúrese usted una boca de cerca de 2.000 varas de diámetro, cuyos bordes destrozados y negros presentan la imagen del Chaos; que a quinientas o seiscientas varas de profundidad se ve elevarse una llama azul con mucho humo; que de rato en rato tiemblan las rocas. Apenas hay por donde acercarse a este lugar de horror y de espanto, que no se vea el observador cercado de peligros. Es necesario subir sobre la nieve, porque toda la boca está cercada de ella, y en más de una parte se forma en falso entre dos rocas vecinas. Yo he visto al Barón en punto de perecer, y dar mis pasos sobre una bóveda de nieve en la orilla del precipicio. Un indio que le precedía libró esta preciosa vida de la muerte. Yo seguía de cerca al Barón, y los dos fuimos los primeros que tomamos la cima. Este viajero tiene coraje, pero lo ví temblar en la extremidad de la roca. Yo partía con él el peligro, no menos temeroso; le ayudé a hacer la observación del barómetro, y descendí. Mr. Bonpland cayó en deliquio tres veces, y me acordé que éste me había dicho que no se me llevaba a Lima y Méjico por débil. Tuve la satisfacción de que viese el Barón que no era dama y sabía escalar las montañas más terribles...".

Los apartes de Caldas, en las cartas transcritas, pintan, mejor que nadie, cuales fueron las relaciones que tuvo con el célebre sabio y viajero alemán. Quizás Caldas fue injusto en ciertas apreciaciones sobre la conducta y vida del Barón, pero debemos recordar que Caldas había sido creado en un ambiente religioso y colonial, como lo era el de Popayán y Santafe; en cambio Humboldt venía de las Cortes europeas, donde sabían dosificar el placer y el estudio.

Conviene recalcar sobre las razones por las cuales Humboldt no accedió a que Caldas lo acompañara en su viaje. La razón principal es sin duda la que da el mismo Caldas al decir "el carácter de Humboldt y el de Caldas son muy diferentes". De las explicaciones nás pormenorizadas contenidas en el texto de la carta puede juzgarse que dicha diferencia de caracteres era bastante grande, para que de ella pudiesen haber surgido, si acaso, desagrados sensibles en las intimidades no bien evitables en un largo viaje, por malos caminos y posadas primitivas, si acaso las había. A lo menos, muy aventurado sería inculpar a uno de los dos, porque su modo de ser distinto no se avenía al carácter del otro.

A esto debemos agregar otro motivo, que explica en favor de Humboldt la negativa; la deuda de gratitud para con su noble huésped el Marqués de Selva Alegre, quien tenía comprometido al viajero prusiano a llevar en su compañía a su hijo Carlos Montúfar.

Mientras Caldas se internaba en las soledades del Imbabube, los dos europeos continuaron su viaje, pero no por la separación se cortaron las relaciones que subsistían sobre el mismo pie de franca amistad. Entre las cartas dirigidas después por Caldas a Humboldt, hay una que muy especialmente caracteriza el grado de amistad y el modo como el autor interpreta su punto de vista con respecto a los dos. Es la carta fechada en Otavalo, cerca de Ibarra, el 17 de noviembre de 1802, en que, entre otras cosas, dice:

"Mi admiración y veneración crecen por horas; deseo con fervor conocer las observaciones y los trabajos hechos por usted actualmente en la capital del Perú. Tendré la dicha de conseguirlo alguna vez? Demasiado conozco la diferencia que existe en conocimientos y méritos entre los dos, pero estoy convencido de que mis deseos serán cumplidos al fin, por la bondad del corazón de usted. No he observado el último equinoccio, pero sí el solsticio de verano, y pienso ir a principios de agosto para observar el solsticio de invierno y cosechar con esto los frutos de mis trabajos. Cuando llegue a Quito, concluya mis observaciones del próximo solsticio y calcule todo, enviaré a usted mis resultados y le informaré sobre mi método; para que usted me lo corrija y me enseñe. En su carta me da usted noticia exacta de todo lo que ha emprendido hasta Trujillo. Cómo podría yo agradecérselo mejor que con el relato de mis ocupaciones durante los tres últimos meses?".

Quien así escribe -y no hallamos motivo para dudar de la sinceridad de sus palabras - no demuestra animosidad ni resentimiento alguno contra la persona a quien dirige la carta. Por otra parte, ninguno de los contemporáneos y aun después de muerto Caldas, durante muchos años, nadie ha hecho tanta justicia a sus méritos como el mismo Humboldt; comenzando por sus cartas de Quito dirigidas a Mutis, luego en un número considerable de citas y elogios, que en seguida detallamos, y en fin en repetidas expresiones durante toda su vida, en que no dejaba de lamentar la pérdida de tan preciosa existencia y de condenar el imperdonable sacrificio.

En efecto, Humboldt en la compilación de observaciones astronómicas que arregló Oltmans dice así:

"M. Caldas, americano de nacimiento, observa igualmente la latitud de Popayán por medio de gnomons... M. Caldas, de quien no se elogiará bastante el celo por el progreso de la geografía, se sirvió para tomar las alturas correspondientes del sol, de un cuarto de círculo de madera. El observador fue obligado a construir él mismo sus instrumentos, según las descripciones incompletas que él encontró en las obras de astronomía... M. Caldas observó la latitud del Gigante con instrumentos construídos por él mismo, a saber, un cuarto de 
círculo de 16 pulgadas, y un gnomon de cinco pies... Para fijar la longitud, M. Caldas observó, con un cuidado extremo, el eclipse de luna del 3 de diciembre de 1797, se sirvió para esto de un anteojo acromático de treinta pulgadas y de un buen reloj."

Al hablar del Pital dice que las observaciones de Caldas son de resultados preciosos para la geografía de la América Meridional.

(Voyage de Humboldt et Bonpland. Quatrieme partie. Astronomie. A. Paris, chez F. Schoell, libraire, rue des Posses-Saint-Germain l'Auxerrois. No. 29, 1810. Recuel d'observations astronomiques, d'operations trigonometriques et de mesures barométriques, faites pendant les cours d'un voyage aux regiones equinoxionales du nouveau-continent depuis 1799 jusqu'au 1803 par Alexander de Humboldt redigées et calculées, aprés les tables les plus exacts par Jabbo Oltmanns. Ouvrage auquel on a joint des recherches historiques sur la position de plusieres point importants pour les navigateurs et pour les geographes).

En la introducción el autor hace notar que a las 235 observaciones de Humboldt ha agregado las de varios autores, entre los cuales cita a Caldas; y en el trabajo titulado "Sobre la altura de varios lugares del Continente" dice:

"Después de haber terminado el cálculo del nivela. miento de $\mathrm{M}$. de Humboldt, he emprendido calcular, según la fórmula de M. Laplace, las alturas barométricas que se encuentran esparcidas en las obras de Bouguer, La Condamine, don Jorge Juan, Ulloa y Chappe. He agregado diez y seis puntos medidos por $M$. Caldas, e indicadas en un manuscrito que este joven sabio americano comunicó a M. de Humboldt durante su residencia en Quito."

$\mathrm{Y}$ en el cuadro de aquellas medidas coloca primero las hechas por Caldas, que son las de La Mesa, Portillo, Pital, La Eme (montaña). Poblazón, Buenavista (montaña), Paispamba, Estrellas (montaña), Tambores, Cantera de Sombreros, Las Juntas, Coconuco, Llano Largo, La Herradura, Venta-Quemada y Quarchu.

Ahí están las alturas barométricas, observadas en líneas; la temperatura supuesta en termómetro centígrado; la altura absoluta en toesas y la diferencia correspondiente al aumento de un grado en la temperatura indicada.

\section{Humboldt, en su "Nivelación barométrica" dice:}

"Agregando a los resultados que ofrezco en este momento a los físicos, algunas medidas hechas por $\mathrm{La}$ Condamine y Bouguer, las del señor Caldas, y las pocas alturas que se conocen sobre el territorio de los Estados Unidos, se encontrará que el Nuevo Continente presenta cerca de quinientos puntos cuya elevación sobre el nivel del mar ha sido determinada barométricamente. Dudo que en toda el Asia se conozcan más de cin- cuenta, y sin embargo las naciones más civilizadas de Europa tienen allí colonias desde hace tres siglos! Cuán importante sería fijar la altura absoluta del interior de la Persia y del Tibet!... Me he servido de tiempo en tiempo, de un aparato en el cual se hace la experiencia primitiva de Torricelli, aplicando sucesivamente tres o cuatro tubos llenos de mercurio y sin aire a una escala móvil y tomando el término medio de las alturas observadas."

\section{Al pie pone esta nota:}

"Es a las bondades del célebre Mutis, en Santafe, a las que debo este aparato, del cual él se ha servido en sus excursiones botánicas. Será útil recordar aquí que he descrito hace diez años, en el Diario de Física, un barómetro de varios tubos, de los cuales uno puede ser sustituído al otro en caso de un accidente, aun sobre la cima de una montaña."

En las posiciones geográficas hay catorce de las cuales dice:

"Estas posiciones se fundan sobre las observaciones de don José Caldas, que he calculado en 1806".

Ahí están Gigante, Garzón, Timaná, San Agustín, Pital, Carniceras (Carnicerías?), Yagua, Boquerón, Naranjar, Suaza, Ceja, Hato de Alejo, Paycol y Cerrillos.

De lo anterior se deduce cuan eficaz fue la colaboración de Caldas en las tareas del ilustre prusiano, y como éste así lo reconoció siempre y de manera pública.

Por su parte Caldas siguió preocupándose de los viajes de Humboldt. En carta dirigida a Mutis el 20 de febrero de 1803 le dice:

"Las noticias que frecuentemente hemos recibido del señor Barón nos enseñan que la fama del Perú y de su capital han sido exageradas por todos los viajeros que le han precedido, y que no merece la visita de un filósofo; él se halla al presente en Guayaquil, próximo a embarcarse para Acapulco; dice que el suelo es fecundo en producciones naturales, que casi ha agotado Tafalla y Manzanilla, continuadores de la Flora del Perú."

En carta al mismo Mutis de abril 21 de 1803 dice:

"El señor Barón de Humboldt me ha escrito misivas llenas de expresiones de cariño, y me manda a presentar un cajón de libros de historia natural y de matemáticas, entre ellos muchos alemanes. Yo no entiendo esta lengua, y he pensado remitírselos a usted, en compañía de las plantas. Aun no llegan, y quien sabe si se perderán con las revoluciones de Riobamba”.

Finalmente anotamos que Caldas escribió una prefación al trabajo de Humboldt sobre la Geografía de las Plantas, que éste envió a Mutis, y que más tarde fue publicado en "El Semanario" de Caldas.

Tales fueron las relaciones entre Humboldt y Caldas. 